\title{
Discurso antivacina no YouTube: a mediação de influenciadores
}

\section{Anti-vaccine discourse on YouTube: the mediation of influencers}

\section{Discurso antivacunas en YouTube: la mediación de influenciadores}

\author{
Antonio Marcos Pereira Brotas ${ }^{1, a}$ \\ brotas@bahia.fiocruz.br | http://orcid.org/oooo-0001-8438-2445 \\ Márcia Cristina Rocha Costa ${ }^{2, a}$ \\ marciarocha.jor@gmail.com | http://orcid.org/oooo-0002-9455-84.3X \\ Júnia Ortiz ${ }^{1, b}$ \\ junia.ortiz@gmail.com | http://orcid.org/o0oo-0002-9129-0271 \\ Caio Costa Santos ${ }^{1, c}$ \\ caiocostasnts@gmail.com | https://orcid.org/oooo-0001-6671-4338 \\ Luisa Massarani ${ }^{3, d}$ \\ luisa.massarani@fiocruz.br | http://orcid.org/o0oo-0002-5710-7242 \\ ${ }^{1}$ Fundação Oswaldo Cruz, Centro de Pesquisa Gonçalo Moniz. Salvador, BA, Brasil. \\ 2 Universidade Federal do Recôncavo da Bahia, Centro de Artes, Humanidades e Letras. Cachoeira, BA, Brasil. \\ ${ }^{3}$ Fundação Oswaldo Cruz, Casa de Oswaldo Cruz. Rio de Janeiro, RJ, Brasil. \\ a Doutorado em Cultura e Sociedade pela Universidade Federal da Bahia. \\ b Doutorado em Comunicação e Cultura Contemporâneas pela Universidade Federal da Bahia. \\ c Graduando em Jornalismo pela Universidade Salvador. \\ d Doutorado em Educação, Gestão e Difusão em Biociências pela Universidade Federal do Rio de Janeiro.
}

\section{RESUMO}

Este artigo apresenta resultados de uma pesquisa sobre o discurso antivacina em 14 vídeos mais relevantes no YouTube exibidos em 2018 e 2019, considerando a quantidade de visualizações, likes, dislikes e comentários. O estudo identifica argumentos e sentidos construídos pelos mediadores, a partir da perspectiva natural, que associa a vacina à ideia de veneno, riscos e morte; e da perspectiva política, que aciona liberdades individuais e planos de poder para redução populacional e lucro da big pharma. Na interseção entre as duas perspectivas, aspectos religiosos compõem a moldura dos discursos. A análise qualitativa e quantitativa aponta a necessidade de investir em estratégias de comunicação que esclareçam e desconstruam as informações falsas ou distorcidas disseminadas. Também sinaliza a importância de diálogo com um público descrente com instituições políticas, científicas e midiáticas, em que a ameaça de punição pela lei não é obstáculo para recusa ou hesitação vacinal.

Palavras-chave: Desinformação; Antivacina; Discurso; YouTube; Influenciadores. 


\section{ABSTRACT}

This article presents results from a research on anti-vaccine speech in 14 of the most relevant YouTube videos showed in 2018 and 2019, considering the amount of views, likes, dislikes, and comments. The study identifies arguments and meanings constructed by the mediators, from the natural perspective, which associates vaccine with the idea of poison, risks and death; and the political perspective, which triggers individual freedoms and power plans for big pharma's population reduction and profit. At the intersection between the two perspectives, religious aspects make up the frame of the discourses. The qualitative and quantitative analysis points to the need to invest in communication strategies that clarify and deconstruct the disseminated false or distorted information. It also signals the importance of dialogue with an unbelieving public with political, scientific and media institutions, where the threat of punishment by law is no obstacle to vaccine refusal or hesitation.

Keywords: Misinformation; Anti-vaccine; Speech; YouTube; Influencers.

\section{RESUMEN}

Este artículo presenta los resultados de una investigación sobre el discurso antivacunas en los 14 videos de YouTube más relevantes mostrados en 2018 y 2019, considerando la cantidad de visitas, me gusta, disgustos y comentarios. El estudio identifica argumentos y significados construidos por los mediadores, desde la perspectiva natural, que asocia la vacuna con la idea de veneno, riesgos y muerte; y la perspectiva política, que desencadena las libertades individuales y los planes de poder para la reducción de la población y las ganancias de las grandes farmacéuticas. En la intersección entre las dos perspectivas, los aspectos religiosos constituyen el marco de los discursos. El análisis cualitativo y cuantitativo apunta a la necesidad de invertir en estrategias de comunicación que aclaren y deconstruyan la información falsa o distorsionada difundida. También señala la importancia del diálogo con un público incrédulo con instituciones políticas, científicas y mediáticas, donde la amenaza de castigo por ley no es un obstáculo para el rechazo o la vacilación de la vacuna.

Palabras clave: Desinformación; Antivacina; Discurso; YouTube; Influenciadores.

Este artigo compõe o dossiê Comunicação, Saúde e Crises Globais: parte 2.

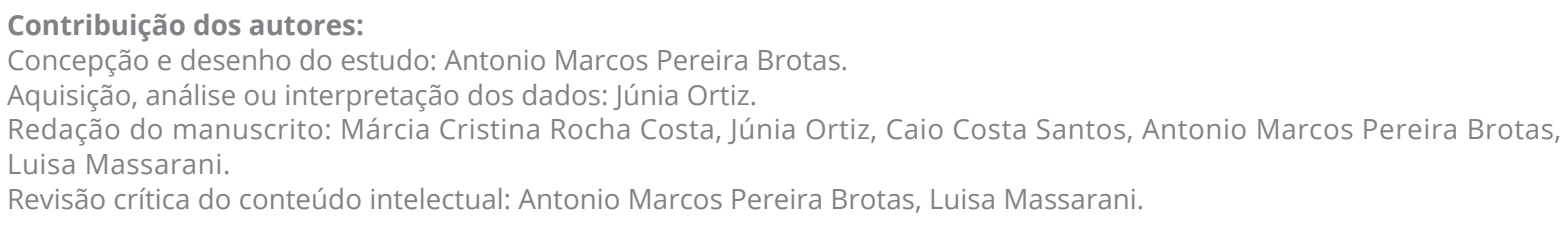




\section{INTRODUÇÃO}

O discurso antivacina tem sido um desafio não só para instituições e profissionais da saúde, mas para toda a sociedade, diante do aumento de casos de doenças já erradicadas, como o sarampo. O problema ganhou proporções tão elevadas que a Organização Mundial de Saúde (OMS) elencou a recusa ou hesitação vacinal como uma das dez maiores ameaças à saúde pública. Em 2018, mais de 10 mil casos foram registrados no Brasil e até setembro de 2019, 4.476 casos confirmados (BRASIL, 2019). A queda nos índices de cobertura vacinal chegou a ficar abaixo de 50\% em 312 cidades brasileiras, segundo alerta do Ministério da Saúde em meados de 2018. A associação das vacinas a ideias de envenenamento, doenças, morte e teorias da conspiração, a partir de perspectivas distorcidas ou falsas, tem estimulado a recusa ou hesitação vacinal, refletindo no desempenho de políticas públicas de prevenção e controle de doenças.

De acordo com Lemos (2009), a ascensão das mídias sociais fez surgir novas associações e modelos comunicativos, que ampliam a capacidade de produção de conteúdo e interação entre as pessoas. Nesta dinâmica que rompe fronteiras, os discursos e argumentos influenciam na construção do sentido social da vacina (JENKINS; MORENO, 2018). Estudos apontam que o discurso antivacina se alastra com a disseminação de informações falsas ou distorcidas do seu contexto, potencializando seus efeitos adversos e a ausência de efetividade das vacinas, o que influencia na crença dos indivíduos e estimula a hesitação, principalmente de pais que buscam informações na internet (SCHMIDT et al., 2018; MELEO-ERWIN et al., 2017). O sistema de monitoramento do Ministério da Saúde também constatou que $89 \%$ das ocorrências de fake news estão relacionadas com efetividade e risco de vacinas contra HPV, sarampo e febre amarela, além de associação frequente da vacina com autismoi.

O YouTube tem demonstrado ser um importante espaço social para compartilhar o sentimento de hesitação vacinal (YIANNAKOULIAS; SLAVIK; CHASE, 2019). O estudo do discurso antivacina nesta plataforma justifica-se não só pelo seu alcance - mais de dois bilhões de usuários conectados (YOUTUBE, 2021) - mas, principalmente, pela necessidade de identificar os argumentos e sentidos construídos. A compreensão sobre os receios e incertezas que influenciam na recusa ou hesitação é fundamental para estabelecer estratégias de comunicação e convencimento das pessoas sobre a efetividade das vacinas e a importância de tomá-las para saúde coletiva.

Neste trabalho, apresentamos os resultados de uma pesquisa sobre os argumentos antivacina numa amostra de 14 vídeos de língua portuguesa mais relevantes exibidos no YouTube, entre janeiro de 2018 e outubro de 2019. A extração de dados por meio da API da plataforma foi feita com o filtro da palavra vacina, compondo uma base para análise de 2.498 vídeos. Desse total, foram escolhidos os cem vídeos mais relevantes, identificados pela soma da quantidade de visualizações, likes, dislikes e comentários. Assim, a partir da leitura visual e textual dos vídeos, identificamos palavras e expressões frequentes no discurso antivacina presentes no conteúdo da amostra desta pesquisa, que apresenta resultados de análise qualitativa e quantitativa.

\section{O DISCURSO ANTIVACINA: O PASSADO NO PRESENTE}

A hesitação vacinal, caracterizada pelo atraso na aceitação ou recusa da vacina, mesmo que esteja disponível nos serviços públicos, é um conceito definido por um grupo especial criado pela Organização Mundial da Saúde em 2012. Trata-se de um fenômeno complexo, que envolve sentimentos de medo e insegurança em relação a efetividade, necessidade real e riscos da vacina, a desconfiança no sistema de

i O Ministério da Saúde disponibilizou um número de Whatsapp para a população enviar informações falsas virais. Segundo Gabriela Rocha, coordenadora de multimídia da assessoria de comunicação do Ministério da Saúde, 87\% das informações que chegaram no primeiro mês do canal estavam relacionadas à credibilidade da vacina. Informações cedidas no Workshop Trends in News, em 18 de setembro de 2018, no Hotel Comfort Suites Oscar Freire, na Rua Oscar Freire, 1.948, Pinheiros, São Paulo. 
saúde ou na indústria que produz vacina, ou seja, questões de ordem sociocultural, política e pessoais que influenciam na decisão de recusar a vacina ou escolher um esquema alternativo (SUCCI, 2018).

A recusa ou hesitação vacinal não é um fenômeno recente, mas surgiu enquanto movimento de resistência popular desde que a vacina se tornou uma medida de saúde pública. A primeira vacinação gratuita em massa contra varíola foi aplicada em crianças no ano de 1840, na Grã-Bretanha, e se tornou obrigatória em 1853. Desde então, as ligas antivacinação foram criadas na Inglaterra e Estados Unidos em meados do século XIX para contestar a obrigatoriedade da vacina, numa reação de temor da população pelas substâncias que seriam injetadas no corpo saudável. No Brasil, a revolta da vacina é um fato histórico, resultado da combinação de movimentos sociais e políticos no início do século XX, que coincidem com a lei da vacinação obrigatória proposta por Oswaldo Cruz (HOCHMAN, 2011). Como alertam Pôrto e Ponte (2003), este episódio vai além da insatisfação popular contra a política de combate às epidemias de Oswaldo Cruz ou a reforma do espaço urbano do prefeito do Rio de Janeiro, Pereira Passos, que afetou parcelas da população. Trata-se de um fenômeno complexo, que envolve crenças, diferentes concepções políticas, científicas e culturais, capazes de provocar reações de intelectuais, como Rui Barbosa, em defesa da privacidade e da livre determinação ante à obrigatoriedade da vacina.

longe de ser um ato isolado, sujeito apenas aos parâmetros de aferição e decisão da medicina ou das ciências biomédicas, a vacinação é também, pelas implicações socioculturais e morais que envolve, a resultante de processos históricos nos quais são tecidas múltiplas interações e onde concorrem representações antagônicas sobre o direito coletivo e o direito individual, sobre as relações entre Estado, sociedade, indivíduos, empresas e países, sobre o direito à informação, sobre a ética e principalmente sobre a vida e a morte. (PÔRTO; PONTE, 2003, p. 729).

Apesar de todos os consensos científicos sobre os benefícios da vacina na proteção coletiva, demonstrados ao longo do tempo com a erradicação de várias doenças, como a varíola, o movimento antivacina no Brasil se atualiza no mesmo rastro de desinformação e medo do século passado. Com um agravante: a velocidade na circulação de informações falsas ou distorcidas nas mídias sociais, que ganham a adesão de usuários pelo seu sistema de crenças.

Sem depender da mediação dos veículos tradicionais de comunicação de massa para tornar públicos seus pontos de vista, os atores antivacina encontram nas mídias sociais espaço para suas vozes, ao mesmo tempo em que consomem, produzem e compartilham conteúdos diversos muitos deles ancorados em informações falsas em busca de desinformação. O ativismo antivacina cresce nas redes sociais e têm preocupado a comunidade internacional de saúde pública com a também crescente insegurança dos pais em relação à vacina (LARSON, 2011).

A compreensão desse fenômeno passa também pelo processo de midiatização da sociedade, que vai além das inovações trazidas pelas Tecnologias de Informação e Comunicação (TIC's), modificando a forma como as relações sociais são desenvolvidas numa arquitetura como consequência da diversidade comunicacional com novas lógicas de produção, circulação e recepção. Nesse contexto, os dispositivos midiáticos têm influência sobre diversos campos, estruturando ações por meio de operações técnicas, simbólicas e discursivas.

Fontes noticiosas e pluralidade de visões no que diz respeito ao consumo do conteúdo, o jornalismo tem enfrentado um cenário mais competitivo (grandes jornais competem com veículos de pequeno porte) e, ainda, certa desconfiança de uma parcela da audiência, que passa a questionar a verificar a veracidade do conteúdo, confrontando com outras fontes encontradas também no ambiente online. Todas essas práticas corroboram com a ideia de que o que se entende como jornalismo se altera conforme o contexto históricocultural e, acrescentaríamos, tecnológico. Entende-se, portanto, que o modelo conceitual sobre a ação das notícias e sua relação com o público é, em boa medida, transformado pela otimização dos mecanismos 
de busca de notícias e por suas formas de produção. O que transforma seus atributos e seus modelos de autoridade e reconhecimento (ANDERSON; BELL; SHIRKY, 2013; DEUZE; WITSCHGE, 2016).

A dinâmica das mídias sociais permite que a audiência tenha um comportamento ativo para além da interpretação das mensagens, passando a se tornar um ator social que produz e também é responsável pela circularidade de conteúdo, colocando-os em uma zona de contato entre diversos outros atores. Ao se tornarem sujeitos enunciadores de sentido, os interlocutores passam a reconfigurar seus lugares como receptores, tornando-se emissores. A participação na esfera pública está atrelada, em alguma medida, ao domínio de técnicas de produção de conteúdo para disseminação de informações, que podem ser verdadeiras, falsas ou distorcidas, colocando em questão os modelos de autoridade e verdade no jornalismo (HJARVARD, 2014; KARLSSON, 2011).

$\mathrm{Na}$ interação digital, pessoas, grupos, instituições e organizações se articulam e trocam informações, experiências, publicam e compartilham conteúdos, fortalecendo supostas evidências científicas sobre efeitos adversos das vacinas e sua eficácia (SMITH, 2017). A imprensa, que tem papel atuante no agendamento de pautas do setor saúde, na visibilidade e discussão de políticas públicas, tem perdido o seu lugar de referência como mediadora de discursos verdadeiros sobre a realidade, no contexto em que a pós-verdade se sobrepõe aos fatos.

[...] as crenças pessoais, irrefutáveis para muitos, ganharam força frente à lógica e aos fatos e acabaram estabelecendo-se como pressupostos compartilhados pela sociedade, provocando a desordem da opinião pública. Nesse ambiente, surgem novas formas de relacionamento com a opinião pública e consolidam-se os meios de comunicação alternativos (LLORENTE, 2017).

A desinformação é um dos elementos da contemporaneidade que não data a partir do advento dos cibermeios, mas são potencializadas por eles. Uma das formas de desinformação que surgem em meio aos jornais e entre os narradores estudados por essa investigação são as fake news, caracterizadas como o ato de fabricar informações não verdadeiras que imitam ou se apropriam, de alguma maneira, da forma de cobertura midiática (LAZER et al., 2018).

Desde 2016, com a eleição do presidente americano Donald Trump, o termo fake news emergiu com força no debate político e invadiu as discussões acadêmicas, em áreas como comunicação, psicologia, ciência política e computação, a ponto do debate incluir a influência da desinformação nos resultados eleitorais em todo mundo, mobilizando inclusive partidos políticos, movimentos sociais e instituições do judiciário, o que se acentuou com o episódio do Brexit, no Reino Unido (ALLCOTT; GENTZKOW, 2017; DUFFY, 2018). Entre as características das Fake News, sua ambiência digital de convivência lhe permite uma ampla circulação nas redes digitais, onde transitam informações, afetos e identidades (GOMES; DOURADO, 2019).

Apesar do sucesso midiático, o termo fake news foi evitado, principalmente, por analistas e pesquisadores, que buscam entender o fenômeno, pela possibilidade deste ser utilizado pelos próprios produtores de desinformação como arma contra instituições tradicionais da mídia jornalística. Adiciona-se ainda o fato da sua imprecisão conceitual, uma vez que estratégias de desinformação não se limitam ao uso de informações falsas travestidas de símbolos e estruturas discursivas que garantiram credibilidade ao campo do jornalismo.

Wardle e Derakhshan (2017) expressaram contrariedade em relação ao uso do conceito fake news e propõem a utilização de mis-information, quando a disseminação de informações falsas não tem a intenção de causar dano, e dis-information, quando a produção e o compartilhamento de informações falsas, imprecisas ou descontextualizadas é intencional e visa produzir prejuízos aos opositores ou ganhos políticos e econômicos aos seus difusores. Em 2019, os autores defendem o uso do termo desinformação como mais compatível com o que consideram ‘desordem informacional' na contemporaneidade, agravada pela 
emergência das mídias sociais digitais que ocasionaram uma mudança no padrão de produção, distribuição e circulação de informações. Estariam no âmbito da desinformação: sátira e paródia; conexão falsas entre títulos, imagens e legendas; conteúdo enganoso, proveniente de enquadramentos distorcidos; contexto falso, quando conteúdos verdadeiros são exibidos fora dos seu contexto original; conteúdo impostor, quando são distribuídos como originários de instituições de mídia que não o produziu; conteúdo manipulado; conteúdo fabricado. Note-se ainda o caráter digital que caracteriza a desinformação contemporânea.

No campo da saúde, algumas delas têm surgido especialmente associadas às vacinas. Tentativas de construção de narrativas, como associar a vacina a autismo ou afirmar que a vacina contra o HPV causa lesões ao sistema nervoso periférico e central são comuns entre os sites de mídias sociais (WASZAK; KASPRZYCKA-WASZAK; KUBANEK, 2018). Tanto que diversos veículos de comunicação, sejam estritamente institucionais, como no Ministério da Saúde, ou jornalísticos, como a Agência Lupa ou a página Fato ou Fake, do G1, surgem com o objetivo de mitigar a desinformação nas redes ou plataformas de conteúdo. Essas agências são conhecidas atualmente como fact-cheking e vem se legitimando como instrumentos de verificação das informações que viralizam nas redes sociais e pautam o debate público.

Estudos indicam o crescimento do discurso antivacina nas redes sociais desde 2004, quando os blogs se popularizaram, com estudos principalmente na Itália, Inglaterra e Estados Unidos, de onde vem boa parte das referências utilizadas em vídeos brasileiros antivacina no YouTube ${ }^{\mathrm{ii}}$. Conforme apontado por estudo sobre o tema a partir da análise de mensagens e comentários de blogs entre 2006 e 2015, 52\% das postagens desencorajaram a vacina questionando liberdades individuais (MELEO-ERWIN et al., 2017).

Estudos sobre o discurso antivacina que vão desde análise quantitativa sobre a vacinação no YouTube na Itália até o sentimento pró e anti vacina no Canadá (COVOLO et al., 2017; YIANNAKOULIAS; SLAVIK; CHASE, 2019). No Brasil, uma pesquisa exploratória e descritiva realizada com vídeos de língua portuguesa exibidos em canais do YouTube em 2018 mostrou que há vários tipos de narrativas e narradores no YouTube, de produções autobiográficas a vídeos de profissionais de saúde, informativos, institucionais, didáticos e de influenciadores (COSTA et al., 2019). O discurso antivacina foi encontrado, de forma predominante, na categoria de influenciadores, com destaque para vídeos de Jaime Bruning, Rômulo Maraschin e o canal Evangelistas do Apocalipse, que chamaram a atenção pelo alto número de visualizações e apareceram em outro estudo brasileiro sobre vacina no YouTube, publicado pela Avaaz em parceria com a Sociedade Brasileira de Imunizações (SBIm).

Com a nova política do YouTube em relação ao conteúdo publicado, o canal Evangelistas do Apocalipse, muito ativo no discurso antivacina, foi retirado do ar. O site passou a excluir canais que violassem as políticas de segurança e reforçou o combate às fake news em meio ao debate público sobre o impacto de notícias falsas e a ação do 'filtro bolha', que indica vídeos dentro do mesmo conteúdo sem se preocupar com a veracidade da informação. No entanto, essa política do YouTube não tem sido suficiente para evitar a propagação de informações falsas ou distorcidas. Os chamados 'influenciadores' constroem vínculos com suas audiências, dando aos seus seguidores a impressão de envolvimento, de uma troca exclusiva e 'íntima', entendida como o grau de familiaridade e proximidade de um influenciador. O que faz emergir novas formas de comercialização de conteúdos culturais, sociais, políticos, mediante estratégias concorrentes de credibilidade em relação ao jornalismo, através do uso de fontes alternativas, subjetividade na narrativa e crueza na forma de produzir o conteúdo (ARTHURS; DRAKOPOULOU; GANDINI, 2018).

ii Criado em 2005, o YouTube é o principal site de compartilhamento de vídeos na internet e se tornou uma importante mídia social com um bilhão de horas assistidas por dia, perdendo apenas para o Facebook. Neste ambiente, os usuários podem acessar informações, produzir e compartilhar conteúdos diversos, assumindo o papel de mediação numa plataforma em que os canais mais populares ultrapassam os 50 milhões de inscritos. 


\section{METODOLOGIA}

A coleta dos vídeos para este estudo foi realizada com a ferramenta Video List Module disponibilizada no acervo da YouTube Data Tools (RIEDER, 2015). A palavra 'vacina' foi utilizada como filtro na pesquisa específica. Foram coletados todos os vídeos contendo o termo, em português, em 2018 e 2019 (até o final do mês de outubro). No total, 2.498 vídeos, juntamente com seus metadados, compõem a base de análise. Entre os vídeos coletados, 1.198 foram publicados em 2018 e 1.300 em 2019. Foram desconsiderados vídeos sobre vacina aplicada em animais, eliminando do banco todos os casos pertencentes à categoria Pets \& Animals, resultando num total de 2.417 vídeos no período. Os vídeos apresentam média de 42.992 visualizações. As categorias Comedy, Nonprofits \& Activism e Entertainment foram as que obtiveram maior média de visualizações (661.946), (80.883) e (60.855), respectivamente.

\section{Seleção da amostra para análise}

A partir dos dados obtidos foi criada uma nova variável para identificar os 100 vídeos mais relevantes na coleta, através da soma da quantidade de visualizações, quantidade de likes, quantidade de dislikes e quantidade de comentários. Os cem vídeos foram organizados em um ranking de interações a partir do qual foram selecionados aqueles contendo discurso antivacina, identificados por meio de um padrão de expressões narrativas e palavras-chave como 'risco', 'verdade', 'morte', 'veneno', 'autismo', 'reduzir população', 'redução populacional', conforme apontado por estudos anteriores (TANGHERLINI et al., 2016). Dos 100 vídeos mais relevantes de toda a amostra, 14 contém discurso antivacina e foram selecionados para compor o corpus de análise deste estudo. Os detalhes referentes aos vídeos analisados podem ser verificados no Quadro 1. 
Quadro 1 - Vídeos analisados

\begin{tabular}{|c|c|c|c|c|c|c|c|c|}
\hline Canal & Título do vídeo & $\begin{array}{c}\text { Descrição do vídeo } \\
\text { (apenas primeira frase) }\end{array}$ & $\begin{array}{c}\text { Data de } \\
\text { publicação }\end{array}$ & $\begin{array}{l}\text { Visuali- } \\
\text { zações }\end{array}$ & Likes & Dislikes & $\begin{array}{c}\text { Comen- } \\
\text { tários }\end{array}$ & Link \\
\hline $\begin{array}{l}\text { Nova Geração! } \\
\text { Compromisso com a } \\
\text { verdade! }\end{array}$ & $\begin{array}{l}\text { Febre Amarela assista antes } \\
\text { de tomar a vacina! }\end{array}$ & [Sem descrição] & $10-01-2018$ & 1312972 & 28346 & 2354 & 1758 & $\begin{array}{l}\text { https://www.youtube.com, } \\
\text { watch?v=WIcQPPn6Rbk }\end{array}$ \\
\hline $\begin{array}{l}\text { Pátria Evangélica de } \\
\text { Deus }\end{array}$ & $\begin{array}{l}\text { Urgente! Médico faz grave } \\
\text { alerta vacina H1N1 destroí } \\
\text { a imunidade e dá câncer } \\
\text { - será possível??? }\end{array}$ & [Sem descrição] & 03-05-2019 & 727935 & 39609 & 1337 & 3682 & $\begin{array}{l}\text { https://www.youtube.com, } \\
\text { watch?v=BdNM4f3s8tQ }\end{array}$ \\
\hline O natural é melhor & $\begin{array}{l}\text { Vacina da Febre Amarela, } \\
\text { tomar ou não tomar? } \\
\text { Dr. Lair Ribeiro }\end{array}$ & $\begin{array}{l}\text { Garanta seu acesso ao } \\
\text { Palavra do Dr. Lair Ribeiro. } \\
\text { [...] }\end{array}$ & $31-01-2018$ & 220897 & 7774 & 241 & 525 & $\begin{array}{l}\text { https://www.youtube.com } \\
\text { watch?v=v jSDTeTwBM }\end{array}$ \\
\hline Verdade Mundial & $\begin{array}{l}\text { Vacinas: Redução } \\
\text { Populacional? }\end{array}$ & $\begin{array}{l}\text { O fundador da Microsoft é } \\
\text { um dos homens mais ricos } \\
\text { do mundo, Bill Gates, }[\ldots]\end{array}$ & $23-20-2018$ & 207468 & 18955 & 512 & 1170 & $\begin{array}{l}\text { https://www.youtube.com, } \\
\text { watch?v=1Haj-CWzytM }\end{array}$ \\
\hline O natural é melhor & $\begin{array}{l}\text { A verdade sobre a febre } \\
\text { amarela e a vacina - Dr Lair } \\
\text { Ribeiro }\end{array}$ & $\begin{array}{l}\text { Garanta seu acesso ao } \\
\text { Palavra do Dr. Lair Ribeiro. } \\
{[\ldots]}\end{array}$ & $31-01-2018$ & 209058 & 7735 & 343 & 368 & $\begin{array}{l}\text { https://www.youtube.com, } \\
\text { watch?v=syA6bkZMd6s }\end{array}$ \\
\hline $\begin{array}{l}\text { Nutrição Alimentos } \\
\text { \& Cia }\end{array}$ & $\begin{array}{l}\text { Vacinas, Ele disse tudo } \\
\text { isso!! Sob juramento em um } \\
\text { tribunal (incrível e tenebroso) }\end{array}$ & $\begin{array}{l}\text { Meu site: https://www. } \\
\text { nutricaoalimentoscia. } \\
\text { com.br/ I http:// } \\
\text { naturopataonline.com.br/ } \\
\text { blog-2/ [...] }\end{array}$ & $20-05-2019$ & 172333 & 10383 & 471 & 1217 & $\begin{array}{l}\text { https://www.youtube.com, } \\
\text { watch?v=YEkJKC5mgBs }\end{array}$ \\
\hline O Melhor para você & $\begin{array}{l}\text { Super Vacina Natural Contra } \\
\text { a Gripe Dr Lair Ribeiro }\end{array}$ & $\begin{array}{l}\text { Neste vídeo o Dr Lair } \\
\text { Ribeiro responde a uma } \\
\text { pergunta sobre como } \\
\text { prevenir e curar a gripe. } \\
\text { [...] }\end{array}$ & $28-08-2018$ & 161725 & 11286 & 118 & 263 & $\begin{array}{l}\text { https://www.youtube.com } \\
\text { watch?v=4IWjrOEp6FA }\end{array}$ \\
\hline Dr. Uronal Zancan & $\begin{array}{l}\text { Eu nunca usei vacina contra } \\
\text { a gripe e nunca vou usar }\end{array}$ & $\begin{array}{l}\text { Neste vídeo eu explico } \\
\text { porque eu nunca usei e } \\
\text { nunca vou usar a vacina } \\
\text { contra a gripe }[. . .]\end{array}$ & 09-05-2019 & 145670 & 14307 & 414 & 1403 & $\begin{array}{l}\text { https://www.youtube.com, } \\
\text { watch?v=hPW061I1mIE }\end{array}$ \\
\hline
\end{tabular}




\begin{tabular}{|c|c|c|c|c|c|c|c|c|}
\hline Canal & Título do vídeo & $\begin{array}{l}\text { Descrição do vídeo } \\
\text { (apenas primeira frase) }\end{array}$ & $\begin{array}{c}\text { Data de } \\
\text { publicação }\end{array}$ & $\begin{array}{l}\text { Visuali- } \\
\text { zações }\end{array}$ & Likes & Dislikes & $\begin{array}{l}\text { Comen- } \\
\text { tários }\end{array}$ & Link \\
\hline Débora G. Barbosa & $\begin{array}{l}12 \text { - A Verdade Sobre a } \\
\text { Indústria Farmacêutica } \\
\text { (Remédios e Vacinas) }\end{array}$ & $\begin{array}{l}\text { Uma das maiores indústrias } \\
\text { no mundo é a farmacêutica, } \\
\text { ligada através de outros } \\
\text { setores como comidas } \\
\text { transgêneros (GMO), } \\
\text { produção de agrotóxicos e } \\
\text { até mesmo de armas. [...] }\end{array}$ & $23-05-2019$ & 123932 & 18218 & 283 & 2041 & $\begin{array}{l}\text { https://www.youtube.com/ } \\
\text { watch?v=M9T_GEmLkXg }\end{array}$ \\
\hline U mió que tá teno & $\begin{array}{l}\text { A Veja a verdade por } \\
\text { detrás da vacina da febre } \\
\text { amarela I Hangout Dr Lair } \\
\text { Ribeiro. }\end{array}$ & Febre Amarela vacina & $31-01-2018$ & 110254 & 6745 & 184 & 390 & $\begin{array}{l}\text { https://www.youtube.com/ } \\
\text { watch?v=KdCCbazbKAI }\end{array}$ \\
\hline Ciência de Verdade & $\begin{array}{l}\text { 243(4) - Como Reduzir os } \\
\text { Efeitos das Vacinas (4/4) }\end{array}$ & $\begin{array}{l}\text { Este vídeo representa } \\
\text { minhas considerações finais } \\
\text { sobre os últimos três vídeos } \\
\text { publicados no canal (Partes } \\
1 / 4,2 / 4 \text { e } 3 / 4) .[\ldots]\end{array}$ & $05-02-2018$ & 101269 & 10172 & 189 & 1130 & $\begin{array}{l}\text { https://www.youtube.com/ } \\
\text { watch?v=080f5yorvK0 }\end{array}$ \\
\hline Firmeza da Verdade & $\begin{array}{l}\text { A verdade sobre a Febre } \\
\text { Amarela: vacina é armadilha! } \\
\text { A doença tem cura! - Jaime } \\
\text { Bruning }\end{array}$ & Inscreva - se: $[\ldots]$ & $17-01-2018$ & 86080 & 3837 & 169 & 454 & $\begin{array}{l}\text { https://www.youtube.com/ } \\
\text { watch?v=XamK89sp_QU }\end{array}$ \\
\hline Verdade Revelada & $\begin{array}{l}\text { Nós avisamos sobre a vacina } \\
\text { contra Febre Amarela!!! }\end{array}$ & $\begin{array}{l}\text { Urgente ! Tá ligado na } \\
\text { Febre Amarela ? Gente ! } \\
\text { isso é muito sério, tem } \\
\text { muita gente levando isso na } \\
\text { brincadeira e não dando a } \\
\text { devida importância para se } \\
\text { prevenir. [...] }\end{array}$ & $26-01-2018$ & 76933 & 3257 & 173 & 543 & $\begin{array}{l}\text { https://www.youtube.com/ } \\
\text { watch?v=QYiJD3naqII }\end{array}$ \\
\hline Terra Plana Reloaded & $\begin{array}{l}\text { A criminalização da ciência } \\
\text { de verdade! | Riscos das } \\
\text { vacinas! | Entrevista com a } \\
\text { PhD Judy Mikovits! }\end{array}$ & $\begin{array}{l}\text { Apoia-se do canal: https:// } \\
\text { apoia.se/terraplanareloaded } \\
\text { Nesta entrevista chocante a } \\
\text { bióloga molecular, Judy A. } \\
\text { Mikovits, PhD, revela [...] }\end{array}$ & 08-07-2019 & 51500 & 10362 & 55 & 1009 & $\begin{array}{l}\text { https://www.youtube.com/ } \\
\text { watch?v=cLYctMPS5-M }\end{array}$ \\
\hline
\end{tabular}

Fonte: elaboração dos autores. 
A fim de avaliar o modo como o discurso antivacina é construído e apresentado por parte dos produtores deste tipo de conteúdo, analisamos, inicialmente, os termos recorrentes nos títulos dos vídeos e canais. A partir da análise da frequência dos termos utilizados, construímos um ranking e destacamos os 10 termos mais frequentes nos títulos e canais, a fim de auxiliar na identificação dos principais temas envolvendo o discurso antivacina. O termo 'verdade' aparece como o mais recorrente nos nomes dos canais e um dos mais frequentes nos títulos dos vídeos, além da palavra 'vacina'/'vacinas', 'febre' e 'amarela', como podem ser verificados na Figura 1 e Figura 2.

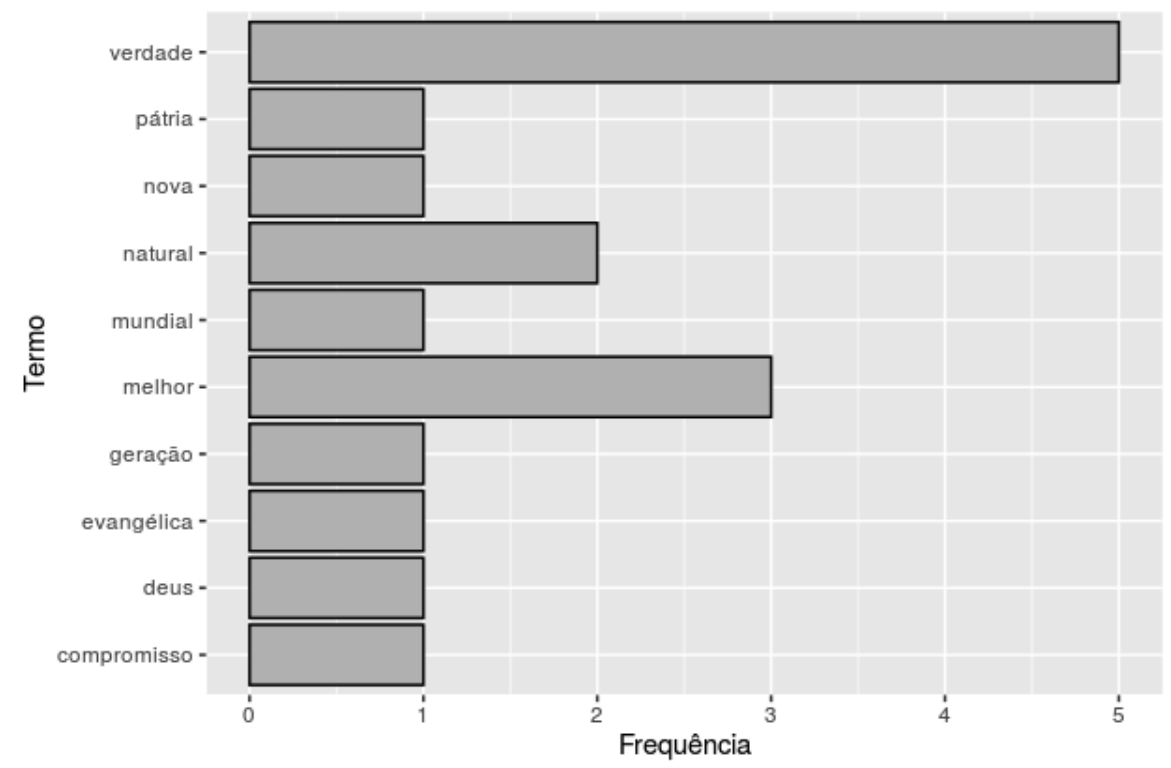

Figura 1 - Termos recorrentes nos nomes dos canais Fonte: elaboração dos autores.

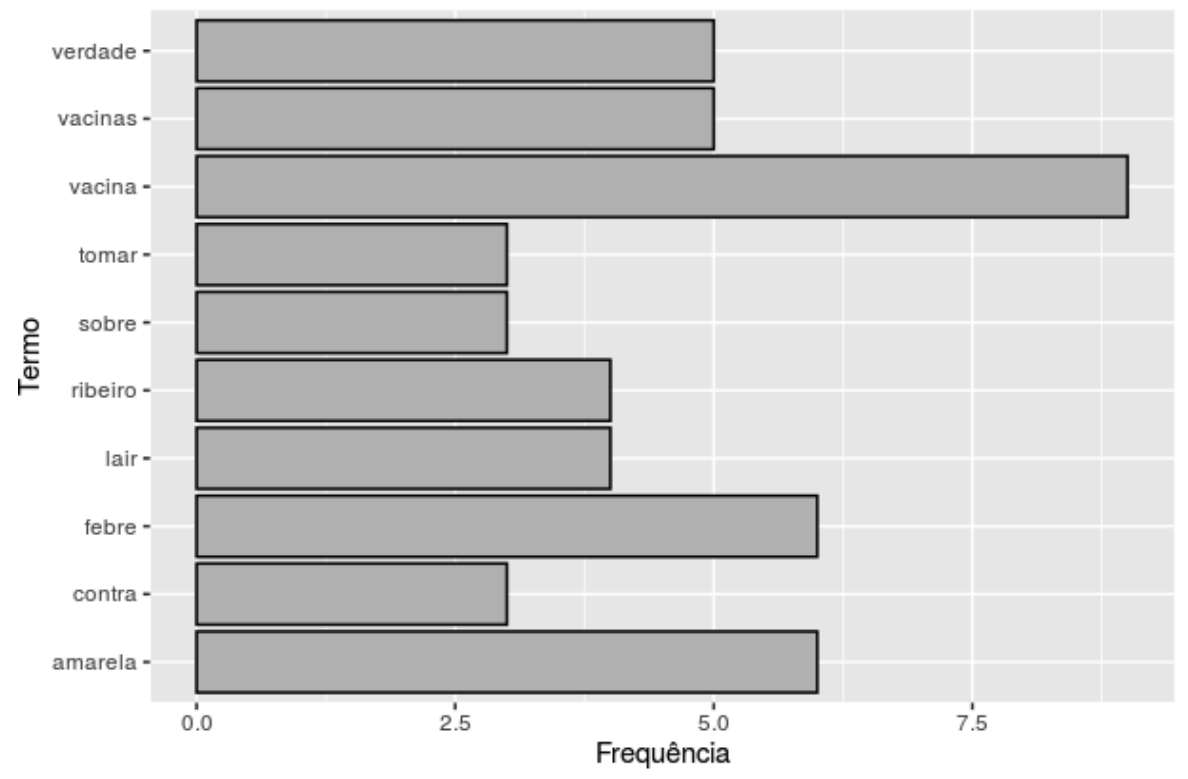

Figura 2 - Termos recorrentes nos títulos dos vídeos Fonte: elaboração dos autores. 


\section{O DISCURSO ANTIVACINA NO YOUTUBE}

A vacina contra febre amarela foi a que teve maior repercussão nos vídeos desta amostra, em função dos surtos ocorridos no Brasil desde 2016. Os termos 'febre' e 'amarela' são os mais citados depois da palavra vacina nos títulos dos vídeos. O discurso dos narradores antivacina no YouTube demonstra a descrença nas instituições, sejam do Estado, políticas, científicas ou midiáticas. Dessa forma, tomando a saúde na perspectiva biomédica hegemônica como uma responsabilidade individual, os narradores antivacina se pautam pela busca de uma verdade sobre as vacinas por conta própria, principalmente a partir de relatos pessoais e/ou opiniões com base em crenças religiosas e terapias naturais (CZERESNIA; MACIEL; MALAGON OVIEDO, 2013).

Além de sua significativa frequência nos nomes dos canais (ver Figura 1), a palavra verdade é também um termo recorrente dos mediadores antivacina, que geralmente adotam a postura de quem detém uma verdade oculta para a maioria da população, nos moldes de uma teoria da conspiração. Os argumentos buscam alertar e convencer as pessoas sobre os riscos da vacina, propondo a recusa como forma de se proteger de substâncias venenosas ou de uma ação global para reduzir a população em consonância com uma suposta nova ordem mundial. Assim, conduzem as narrativas disseminando imagens, textos e depoimentos do movimento antivacina, sem contestar ou duvidar da veracidade das informações difundidas na internet, mas aceitando-as como verdades que precisam ser denunciadas, como a associação das vacinas a transtornos mentais, ao câncer ou a um plano de eugenia lenta e dissimulada. Ao jornalismo, ao contrário, é atribuído o papel de produtor e difusor de fake news, desconsiderando, por completo, sua autoridade sociocultural.

O que leva alguns setores da sociedade a não se vacinarem atualmente tem base em motivos filosóficos, medo de reações adversas, por orientação médica e, até mesmo, embora em menor escala, por motivos religiosos, conforme apontado por estudos anteriores (LEVI, 2013).

A partir do seu sistema de crenças, esses atores conduzem as narrativas ressaltando aspectos socioculturais e ambientais, incertezas científicas, questões morais e de liberdades individuais. No conjunto da amostra, percebe-se um discurso antivacina em duas perspectivas predominantes: o plano natural, centrado em filosofias de vida e práticas de cura alternativas; e o plano político, que envolve interesses dos governos, das empresas, das instituições científicas e midiáticas. $\mathrm{O}$ aspecto religioso está presente como um ponto de interseção entre as duas perspectivas, seja de forma explícita no nome do canal ou no conteúdo dos vídeos exibidos.

\section{A perspectiva natural do discurso antivacina}

A ideia de vacina associada a veneno, causa de doenças e agressão ao corpo é predominante no discurso antivacina, principalmente nos vídeos exibidos em canais voltados para terapias naturais e também religiosos. Essa combinação é bem exemplificada pelo vídeo narrado por Jaime Bruning1, campeão de interações no ranking dos 14 vídeos mais relevantes desta amostra. No canal 'Nova Geração. Compromisso com a Verdade' ele apresenta receita de antibióticos naturais - combinação de folha de couve, maçã, limão, alho, mel e água - para evitar contrair ou curar febre amarela e dengue. O vídeo é uma produção precária, numa edição em que aparece a foto de Jaime com a voz dele alertando sobre a pesquisa que fez na internet a respeito da febre amarela e ainda aborda a vacina contra a gripe como prova de que as pessoas ficam doentes depois que tomam a vacina.

Em outro depoimento exibido no canal Pátria Evangelista de Deus, antecedido e encerrado com passagens bíblicas, Jaime Bruning, apresentado em sua página na internet como terapeuta holístico, aparece sentado num sofá e vestido de branco. No título do vídeo, ganha a referência de médico: ‘Urgente! Médico faz grave 
alerta vacina H1N1 destrói a imunidade e da câncer -Será possível ???' (sic)'. Em tom de alarme na voz e na trilha sonora que acompanha todo o vídeo, este mediador tem como referência os discursos antivacina dos Estados Unidos na internet para basear as suas pesquisas sobre a vacina, além de livros publicados no Brasil de autoria de Bento da Conceição, chamado de profeta por uma igreja em Santa Catarina: “[...] A vacina destrói o sistema que Deus colocou em você [...]” (FEBRE..., 2018). “[...]. Antigamente não tinha vacina. As vacinas são venenos que entram dentro do corpo" (URGENTE!..., 2019).

$\mathrm{O}$ argumento religioso em relação à saúde do corpo tem raízes numa concepção mágico-religiosa da Antiguidade que entendia a doença como uma maldição que se instala no organismo por causa do pecado. Na Idade Média, no período entre os séculos V e XV, religião e prática médica se misturavam. A concepção de doença estava ligada ao pecado e a cura resultava da fé cristã (SCLIAR, 2007). Ao evocar a religião, o discurso antivacina retoma argumentos já utilizados antes mesmo da descoberta da vacina contra a varíola, quando a inoculação, ou seja, a prática de introduzir algo no organismo era considerada pecaminosa. Os primeiros casos de recusa da vacina contra a varíola na Inglaterra e na Suécia ocorreram com o argumento de que a vacinação seria um pecado porque mudaria os desígnios de Deus se alguém tivesse que morrer de varíola (LEVI, 2013).

No conjunto da amostra, o discurso antivacina ganha o reforço de médicos brasileiros contrários ao esquema de vacinação atual, defendendo a restrição a determinadas vacinas em função do impacto e/ou enfraquecimento do sistema imunológico, principalmente de crianças e idosos. Essas vozes questionam a efetividade das vacinas contra febre amarela e gripe, como é o caso do doutor Lair Ribeiro que, explicitamente, não recusa, mas, implicitamente, propõe a hesitação vacinal diante dos seus efeitos adversos. Esse mediador aparece como fonte de referência em quatro vídeos publicados pelos canais 'O natural é melhor', 'O melhor pra você' e 'U mió que ta teno', que sugerem conteúdos voltados para terapias e curas naturais.

Alguns vídeos são trechos de hangout realizado no dia 30 de janeiro de 2018, numa produção vinculada a um projeto da Academia Lair Ribeiro, cujo nome associa o médico ao conhecimento científico, apresentado também como professor e pesquisador. A narrativa valoriza a explicação de termos técnico-científicos sobre a febre-amarela, seus sintomas e formas de contágio para, em seguida, abordar sobre os riscos da vacina contra a doença e seus efeitos adversos. Nesta mediação, o médico aciona argumentos de autoridade médica e científica para ressaltar limites e incertezas da ciência, bem como questões bioéticas, como a incoerência da mesma carga viral nas vacinas para crianças e adultos, construindo assim o seu argumento de restrição à vacina para quem está em área de risco e precisa pagar um preço com a saúde:

[...] Se eu tenho um indivíduo de 140kg e eu tenho um bebê de nove meses, eles vão receber a mesma carga. Não tem uma vacina só pra criança e uma vacina pro adulto. É a mesma vacina [...] Eu acho que você não precisa ser nenhum engenheiro brilhante da Nasa pra começar a perceber que há uma discrepância dar a mesma carga virótica para um bebê de 9 meses e um indivíduo com 20, 18 anos de idade cheio de saúde e força. Pára pra pensar! (VEJA..., 2018).

O argumento de enfraquecimento do sistema imunológico pela vacina é confrontado por estudos que comprovam a capacidade de resposta das crianças - desde o nascimento - a um alto número de antígenos, que permitem a formação de anticorpos específicos diversos. Um estudo realizado na Alemanha com 496 crianças vacinadas e não vacinadas mostrou que as vacinas não aumentam o risco de infecção. Pelo contrário, as crianças imunizadas nos três primeiros meses de vida tiveram menor número de infecções do que as não vacinadas (LEVI, 2013). Apesar dos benefícios coletivos da vacina, o conceito de vacinose, que atribui o desencadeamento de doenças agudas ou crônicas após o recebimento de vacinas, está presente no discurso de médicos que se vinculam a uma linha de atuação natural, como Lair Ribeiro. 
[...] Apresentador: um termo novo aqui pra mim, dr. Lair. O que é vacinose?

Lair: Vacinose é uma doença secundária à vacina. Então vc não tinha nada, vc tomou a vacina e vc pode, digamos, desenvolver uma febre amarela vacinal, causada pela vacina, como já deve ter ouvido casos de gente que desenvolveu poliomielite, paralisia infantil. Aliás, hoje, a principal causa de paralisia do mundo é a vacina porque ela foi erradicada. Então, é também um vírus atenuado. Posso ter sim. É raro? É raro. (VEJA..., 2018).

O conceito de vacinose divide opiniões entre homeopatas favoráveis e contrários à vacina, mas a oposição à vacina não é recomendada pelos autores clássicos da homeopatia, portanto, ligados a uma medicina alternativa. Os que seguem essa linha médica homeopática consideram incoerente a contraindicação da vacina, uma vez que o nível de imunidade coletiva reduz o risco de adoecer entre os não vacinados (LEVI, 2013). Graças aos benefícios de novas vacinas na segunda metade do século XX, boa parte da população jovem brasileira não conviveu e não guarda a memória de doenças como sarampo, cachumba e rubéola, que marcaram a infância de várias pessoas que hoje têm mais de 50 anos de idade. Mesmo assim, a superioridade da imunidade natural - produzida pela própria doença - é um argumento comum na prevenção de doenças imunopreveníveis por vacinas gratuitas nos postos de saúde.

O Dr. Uronal, por exemplo, assume explicitamente o discurso contra a vacina da gripe em seu canal. Ele recorre às incertezas, riscos e dúvidas sobre efetividade da vacina, a partir da interpretação do resultado de um artigo de revisão do Centro Cochrane ${ }^{\mathrm{iii}}$, que indicaria a ineficácia da vacina em 98,6\% dos casos. Assim como Lair Ribeiro, Dr. Uronal também indica a vitamina D como uma vacina natural. Vestido de roupa branca, num cenário com estantes de livros ao fundo, o depoimento do Dr. Uronal fortalece o discurso antivacina e a hesitação vacinal, principalmente quando se trata de um médico também idoso, como boa parte do público-alvo das campanhas contra a gripe. Neste caso, a vacina é associada a uma agressão ao corpo e não à prevenção ou saúde: "Quanto mais alto for o nível da tua saúde, menos precisas agredir o seu corpo com vacinas contra a gripe. Eu já falei pra vocês e vou repetir: eu nunca tomei e nunca vou tomar vacina contra a gripe" (EU..., 2019).

Dentro da perspectiva natural, o vídeo Como reduzir os efeitos das vacinas, exibido no canal Ciência de Verdade faz associação entre vacina e envenenamento, tomando como referência para suas evidências o filme Vaxxed (Vacinados - do encobrimento à catástrofe), livros escritos por autores americanos também são citados como referência de informações sobre vacinas, apontando a relação com autismo e formas de atenuar os prejuízos ao organismo, como a dieta de comidas vivas. Ao recomendar o consumo diário de óleo de fígado de bacalhau e comidas fermentadas (chucrutes e kefir) para fortalecer a imunidade das crianças vacinadas, este narrador afirma que sente culpa por ter vacinado os filhos.

A relação entre vacinas e autismo, argumento muito comum no ativismo antivacina, também é abordada neste vídeo exibido no canal Ciência de Verdade, que coloca em dúvida consensos científicos, refutando a ideia de prejuízo em relação à quantidade de vacinas ou a necessidade de retardar a sua aplicação. O filme utilizado como evidência pelo mediador é um documentário dirigido pelo médico britânico Andrew Wakefield, que teve o registro cassado depois de um estudo fraudulento associando a vacina tríplice viral a casos de autismo. O estudo chegou a ser publicado no periódico Lancet, mas foi desmascarado pela comunidade científica. Recentemente, Robert de Niro, que tem um filho autista e é um dos fundadores do Festival de cinema de Tribeca, em Nova York, censurou a exibição do filme para evitar propagar informação falsa.

O discurso antivacina na perspectiva natural utiliza uma estratégia narrativa que se apropria das concepções de movimentos naturalistas da segunda metade da década de 1970, com o aumento da demanda por práticas terapêuticas, médicas e de cuidado à saúde. No contexto da contracultura, na emergência de

iii O link deixado no canal no dr. Uronal questiona a efetividade da vacina dizendo que há uma diferença baixa entre quem se vacinou e quem não se vacinou. Não há relação entre eventos adversos e a vacina contra a gripe. 
novos paradigmas em saúde, o naturismo rejeitava a medicina tecnificada, formas invasivas para tratamento de doenças, defendendo o consumo de remédios naturais e não químicos, afirmando a força curativa da natureza (NOGUEIRA; CAMARGO JUNIOR, 2007). Ao associar essas concepções do naturismo com o discurso antivacina, os atores desviam o sentido de prevenção da vacina, realçando ideias de veneno, risco de doença, risco de morte, práticas e crenças individuais de cuidado em detrimento da saúde coletiva.

\section{A perspectiva política do discurso antivacina}

A decisão de não vacinar ou selecionar determinadas vacinas para tomar revela conflito entre a ação do Estado e questões culturais, morais e legais. A vacinação obrigatória está prevista no Estatuto da Criança e do Adolescente (ECA), desde 1990, e consta ainda em protocolos de profissionais da saúde como uma proteção à criança, em que a recusa por parte dos responsáveis é considerada negligência parental ou omissão de cuidado (BARBIERI; COUTO; AITH, 2017).

$\mathrm{Na}$ perspectiva política dos atores antivacina do YouTube nesta amostra, percebe-se que, além da reivindicação de liberdades individuais diante do conflito com questões legais e morais, os discursos demonstram desconfiança nas instituições, frequentemente movida por teorias da conspiração que envolvem atores como Bill Gates ou a mídia de forma geral. Na publicação exibida no canal Nova Geração! Compromisso com a verdade! Jaime Bruning fala em um plano mundial de redução populacional, uma nova eugenia para eliminar os pobres e fracos. Esse argumento se repete no segundo vídeo mais relevante da amostra, também de Jaime Bruning, exibido no canal Pátria Evangélica de Deus.

Vacinar os pobres, os feios, os velhos, eles vão ser eliminados aos poucos, eles vão ter câncer, vão ter doenças. Misericórdia, a que ponto nós chegamos! Eu custei a acreditar no que estava lendo. E daí olhando pela internet confirmou tanta coisa. Tá lá pra quem quiser confirmar o que já está tudo de prontidão. Esse genocídio terrível. (URGENTE!..., 2019).

Ainda como argumento contra as vacinas, o narrador aciona o sentido das liberdades individuais, da autonomia, para questionar a obrigatoriedade das vacinas e suas consequências para a saúde humana. "as vacinas são empurradas para as populações pobres e são obrigadas e não se diz o que está dentro, não se informa" [...] a vacina é praticamente obrigatória nas crianças. Os pais perdem até certos direitos sobre as crianças se não vacinar" (URGENTE!..., 2019).

A vacinação em massa é encarada como um plano de poderosos, como Bill Gates, cujo trecho de uma palestra tem sido usado largamente pelos mediadores antivacina para comprovar a teoria de que a vacina é um meio dissimulado e lento para matar pessoas e reduzir a população mundial. Trechos de vídeos usados em outros canais de mediadores também são reproduzidos na mensagem de Jaime, como entrevistas legendadas de fontes americanas sem referência científica alertando para não tomar a vacina.

A crítica à política pública está presente no discurso médico de Lair Ribeiro, ao questionar a efetividade da vacina contra febre amarela. Sua estratégia narrativa faz uso de antecedentes sobre surtos da doença que foram erradicados nos Estados Unidos e no Brasil bem antes do desenvolvimento da vacina. Dessa forma, argumenta que, além dos efeitos adversos, economicamente é mais barato combater o mosquito vetor da doença do que vacinar em massa.

O sentido de liberdade e autonomia também é acionado nas argumentações, principalmente quando se trata de vacinas não obrigatórias, como a de febre amarela e gripe. Na moldura do discurso desse narrador, percebe-se a predominância do sentido de incertezas, ao mesmo tempo em que chama o indivíduo à responsabilidade na decisão sobre tomar ou não a vacina, no seu direito de aceitar ou não os riscos. 
[...] o que eu vou te dar aqui são os componentes do pensamento pra você chegar a sua conclusão o que vai fazer com você e o que vai fazer com a sua família. Essa decisão é sua e ninguém tira ela de você. Certo? Porque não é uma vacina obrigatória. Então, você vai decidir como é que faz.[...] Não existe almoço de graça. Tem um preço pra pagar (FEBRE..., 2018)

Questões bioéticas e jurídicas, como o uso de células fetais nos estudos sobre vacina e a punição para pais que não vacinam os filhos também estão no cerne da argumentação de mediadores no YouTube. No vídeo intitulado 'Vacinas, ele disse tudo isso sob um juramento em um tribunal', exibido no canal Nutrição, Alimento e Cia, o narrador Pedro Júnior compara a vacina a uma sentença do poder público que deixa as pessoas num dilema ético diante da informação do uso de células de fetos que tinham três meses ou mais em estudos sobre as vacinas. Para validar seu julgamento moral, ele usa o trecho de um depoimento do cientista Stanley Plotkin ${ }^{\text {iv }}$ no que seria um tribunal, assumindo o uso de células fetais nas pesquisas.

A hesitação vacinal, diante de questões de ordem cultural, moral ou legal, expõe a complexidade do conflito, tanto no nível individual quanto coletivo. No Brasil, o controle da vacinação é feito por exigências, como a apresentação da cópia da carteira de vacina na matrícula em creche pública ou para garantir acesso ao benefício do bolsa-família. Com base no ECA, uma Ação Civil Pública em 2013, no Estado de São Paulo, determinou um prazo de cinco dias para um casal vacinar os filhos, sob pena de pagar multa diária de um salário mínimo. Porém, a sanção efetiva da lei não é o principal obstáculo vivido pelos casais que não vacinam os filhos, mas a coerção por uma norma socialmente aceita, que reflete numa postura de isolamento e sigilo sobre a decisão de âmbito privado familiar de não vacinar (BARBIERI; COUTO; AITH, 2017).

Ao divulgar com frequência campanhas de vacinação e discursos médico-científicos favoráveis às vacinas, a mídia também surge como vidraça do movimento antivacina e costuma aparecer no centro das críticas dos mediadores como manipuladora, sem interesse em divulgar estudos independentes e a serviço das elites. Interessante notar que as notícias sobre mortes e outros efeitos adversos divulgados pelos meios de comunicação são utilizados como referência para o discurso de risco sobre as vacinas e suas incertezas. O canal Verdade Revelada, por exemplo, usa textos jornalísticos e imagens do portal da Globo para falar das mortes de crianças e idosos, associando a vacina a lixo, morte e agente nocivo para matar e reduzir a população. Na descrição, o canal afirma que tem o objetivo de mesclar os eventos da atualidade com as profecias bíblicas. Ao mesmo tempo em que o canal tece críticas em relação à mídia, acusando-a de terrorismo para fazer as pessoas tomarem a vacina, os títulos das matérias ressaltam seus efeitos adversos, o que levaria a uma hesitação vacinal.

$\mathrm{Na}$ proposta de mostrar a verdade que a mídia tradicional não mostra, o canal Verdade Mundial, comandado pelo jovem YouTuber Ton Muller, fotógrafo de shows, faz questão de assumir uma postura antissistema. Na sua estratégia argumentativa, associa a vacina a um processo atual de eugenia semelhante ao holocausto, cujas imagens de fotos são usadas para ilustrar a narrativa. A sua verdade também se apoia no trecho da palestra de Bill Gates que se tornou elemento de prova no discurso antivacina de redução populacional por meio da vacina. Para reforçar seus argumentos, destaca os supostos investimentos da fundação de Bill Gates em efeitos gráficos mostrando o crescimento acelerado de milhões de dólares aplicados em vacinas e alimentos geneticamente modificados que prejudicam a saúde e causam várias doenças.

Na mesma linha de revelar verdades ocultas para a maioria da população, o vídeo A verdade sobre a indústria farmacêutica, exibido no canal da YouTuber Débora Barbosa também exibe vídeo com suposta base científica e análise crítica. A hesitação à vacina está presente em seu discurso a partir de argumentos

iv Stanley Alan Plotkin é um pesquisador norte-americano e professor emérito de Pediatria da University of Pennsylvania. Ainda, trabalha como consultor para fabricantes de vacinas, como a Sanofi Pasteur, além de, empresas de biotecnologia, organizações sem fins lucrativos e autarquias de saúde. 
que contestam resultados de pesquisa científica, tomando como referência e indicando à sua audiência o livro Captive State, que trata da relação entre a ciência e grandes corporações, como Monsanto e Bayer.

No vídeo, Débora Barbosa utiliza os argumentos do autor como base para a narrativa desenrolar. Apesar de não estar diretamente envolvida com a controvérsia do movimento antivacina, a YouTuber válida a teoria por trás da dita Big Pharma, utilizando esse livro como fonte e prova de suas deduções e inferências sobre a produção da medida profilática, principalmente de grandes nomes da indústria como Bayer para fins comerciais ou de enriquecimento dessa indústria. Débora chega a comentar que os benefícios trazidos pelo leite ao corpo humano são uma falácia produzida por setores de marketing para aumento de verbas das corporações, afirmando que a vacina pertence a mesma lógica. No vídeo, a influencer constrói uma narrativa em que a Big Pharma é o elo entre vacinas, transgênicos e armas químicas, onde encontra-se ainda a redução populacional de Bill Gates, bem como uma suposta relação entre vacinas e doenças mentais no Reino Unido.

Associações simples e descontextualizadas predominam na rede de conteúdos entre os atores antivacina, que seguem, prioritariamente, referência de fontes de pesquisa dos Estados Unidos, terreno fértil para o movimento. Na internet, são disseminados vídeos com depoimentos de fontes americanas, como o da pesquisadora Judy Mikovitz, envolvida em controvérsias científicas que a levaram à prisão e acusações de erros em estudos que foram publicados e depois retratados pela prestigiada revista Science. No vídeo, exibido pelo canal Terra Plana Reloaded e sugerido pelo canal Ciência de Verdade, a fonte fala sobre a falta de controle e supervisão sobre a produção de vacinas e suas consequências para a saúde humana, a partir de um discurso que reúne aspectos morais, éticos, religiosos, políticos e de autonomia sobre o corpo. Enfim, todos os ingredientes que, de um modo geral, norteiam as narrativas dos atores antivacina no YouTube.

O pesquisador Gustavo Bretas, mestre de Epidemiologia pela Escola Nacional de Saúde Pública, mestre de Medicina Tropical na London School of Higiene and Tropical Medicine e consultor de doenças transmissíveis da Organização Panamericana de Saúde (OPAS) no Equador e Suriname, em entrevista para site da Abrasco em 2016, afirmou que para as doenças virais transmitidas pelo Aedes aegypti as atuais estratégias de controle vetorial têm um alto custo e um baixo impacto efeito de controle das doenças, citando o exemplo de países pobres que não obtiveram retornos de saldo positivo no controle vetorial ao investir em gastos com inseticidas (BRETAS, 2017). Afirmou também, que a imunidade populacional é o principal fator de influência na proporção de epidemias. Segundo a Organização Mundial da Saúde (OMS), as vacinas evitam entre 2 milhões e 3 milhões de mortes por ano.

Segundo estudo da Avaaz sobre fake news e vacina, as desinformações disseminadas sobre vacinas são utilizadas em alguns casos como forma de obtenção de lucro:

Uma proporção significativa dos conteúdos que analisamos foi publicada ou criada por sites que publicam artigos negativos ou contendo desinformação sobre vacinas junto com links para curas "milagrosas" e outros produtos de saúde alternativos. Nós observamos que algumas das empresas de mídias sociais proibiram a publicidade em publicações com conteúdo antivacina, mas não agiram para removê-las do conteúdo orgânico que leva os leitores a sites que vendem esses remédios alternativos (AVAAZ; SOCIEDADE BRASILEIRA DE IMUNIZAÇÕES, 2019, p. 7), 


\section{CONSIDERAÇÕES FINAIS}

O discurso antivacina, considerando a amostra dos 14 vídeos mais relevantes sobre o tema publicados no YouTube em 2018 e 2019, aponta duas perspectivas de abordagem: a narrativa vinculada a um modo de vida baseado em terapias e curas naturais e a narrativa de tom político, de questionamento e desconfiança nas instituições políticas, científicas e midiáticas. Nos dois planos, crenças religiosas surgem como ponto de interseção e fortalecimento dos argumentos apresentados.

Ao fazer associações simples e conexões com supostos textos científicos e midiáticos, a vacina é associada a ideias de veneno, morte, risco, insegurança, a partir de argumentos de agressão ao corpo saudável e conflito com filosofias de vida, baseadas em crenças socioculturais e religiosas. Em consonância com o discurso contemporâneo da pós-verdade, aliado e suporte para a disseminação de informações falsas ou distorcidas, uma caixa de pandora é acionada por argumentos de autonomia e liberdades individuais, diante de uma nova ordem mundial para reduzir a população, a partir de uma eugenia controlada pela aplicação da vacina. Essas ideias são frequentemente associadas a planos de poder e lucro, como os investimentos de Bill Gates ou da Big Pharma.

Neste estudo, percebe-se o conflito entre a reivindicada autonomia para o cuidado à saúde do corpo individual e a saúde corpo coletivo, o que aponta a necessidade de comunicação mais efetiva com uma parte da população que convive com dilemas éticos e questões legais. Enquanto o ECA assegura que a vacina é direito das crianças e dever da família, há pais e mães que recusam ou atrasam a vacinação porque preferem práticas naturais ou estão inseguros, descrentes na eficácia da tecnologia de saúde oferecida gratuitamente no serviço público. No caso do discurso médico presente nesta amostra também revela uma postura de conflito até mesmo com a corrente das chamadas medicinas alternativas, quando associam vacina e agressão à saúde.

Nesse contexto, a comunicação exerce um papel fundamental para estabelecer um diálogo mais próximo e dirigido a este público, indo além das campanhas institucionais sobre a vacina e seus benefícios, mas atuando de forma conjunta com outros atores sociais no sentido de esclarecer as dúvidas e mitos que permeiam o discurso antivacina. Os argumentos e sentidos construídos pelo discurso antivacina identificados nesta pesquisa sinalizam a urgência da ação da comunicação com a participação de profissionais de saúde, das diferentes mídias e dos movimentos sociais, que possam contribuir para estratégias de aproximação e convencimento, a partir de um diálogo claro, de respeito, mais preocupado com a prevenção do que uma ameaça punitivista. Afinal, a lei não tem sido obstáculo para a recusa ou hesitação vacinal.

\section{REFERÊNCIAS}

ALLCOTT, Hunt; GENTZKOW, Matthew. Social media and fake news in the 2016 election. Journal of Economic Perspectives, [s. I.], v. 31, n. 2, p. 211-236, 2017. DOI: http://www.doi.org/10.1257/jep.31.2.211. Disponível em: https://www.aeaweb.org/articles?id=10.1257/jep.31.2.211. Acesso em: 10 dez. 2019.

ANDERSON, Christopher W.; BELL, Emily; SHIRKY, Clay. Jornalismo pós-industrial: adaptação aos novos tempos. Revista de Jornalismo ESPM, São Paulo, v. 5, n. 3, p. 30-89, abr./jun. 2013.

ARTHURS, Jane; DRAKOPOULOU, Sophia; GANDINI, Alessandro. Researching YouTube. Convergence: The International Journal of Research into New Media Technologies, [s. I.], v. 24, n. 1, p. 3-15, jan. 2018. DOI: https://doi.org/10.1177\%2F1354856517737222. Disponível em: https://journals.sagepub.com/doi/ abs/10.1177/1354856517737222. Acesso em: 10 dez. 2019. 
BARBIERI, Carolina Luisa Alves; COUTO, Márcia Thereza; AITH, Fernando Mussa Abujamra. A (não) vacinação infantil entre a cultura e a lei: os significados atribuídos por casais de camadas médias de São Paulo, Brasil. Cadernos de Saúde Pública, Rio de Janeiro, v. 33, n. 2, p. e00173315, mar. 2017. DOI: https://doi.org/10.1590/0102-311x00173315. Disponível em: https://www.scielo.br/scielo.php?script=sci arttext\&pid=S0102-311X2017000205004\&lng=pt\&tlng=pt. Acesso em: $10 \mathrm{dez} .2019$.

BRASIL. Ministério da Saúde. Secretaria de Vigilância em Saúde. Boletim Epidemiológico. [Brasília, DF]: Secretaria de Vigilância Sanitária, v. 50, n. 25, set. 2019. Disponível em: https://portalarquivos2.saude.gov.br/ images/pdf/2019/setembro/19/BE-sarampo-25-18set19.pdf. Acesso em: 14 dez. 2019.

BRETAS, Gustavo. Controle vetorial no Brasil é caro e de pouco impacto, diz Gustavo Bretas. [Entreivsta cedida a] Vilma Reis. Abrasco, Rio de Janeiro, 15 dez. 2016. Disponível em: https://www.abrasco.org.br/site/ noticias/saude-da-populacao/controle-vetorial-no-brasil-e-caro-e-de-pouco-impacto-diz-gustavo-bretas/24496/. Acesso em: 10 dez. 2019.

COSTA, Márcia et al. Narrativas e Narradores de Vacinas no YouTube. In: CONGRESSO BRASILEIRO DE CIÊNCIAS DA COMUNICAÇÃO, 42., 02 a 07 set. 2019, Belém. Anais [...]. São Paulo: Intercom, 2019. Disponível em: www.portalintercom.org.br/anais/nacional2019/resumos/R14-1568-1.pdf. Acesso em: $10 \mathrm{dez}$. 2019.

COVOLO, Loredana et al. What arguments on vaccinations run through YouTube videos in Italy? A content analysis. Human Vaccines \& Immunotherapeutics, Austin, v. 13, n. 7, p. 1693-1699, jun. 2017. DOI: https:// dx.doi.org/10.1080\%2F21645515.2017.1306159. Disponível em: https://www.ncbi.nlm.nih.gov/pmc/articles/ PMC5512771/. Acesso em: 10 dez. 2019.

CZERESNIA, Dina; MACIEL, Elvira Maria Godinho de Seixas; MALAGÓN OVIEDO, Rafael Antônio. Os sentidos da saúde e da doença. Rio de Janeiro: Editora Fiocruz, 2013.

DEUZE, Mark; WITSCHGE, Tamara. O que o jornalismo está se tornando. Parágrafo, São Paulo, v. 4, n. 2, p. 06-21, 2016. Disponível em: http://revistaseletronicas.fiamfaam.br/index.php/recicofi/article/view/478. Acesso em: 10 dez. 2019.

DUFFY, Bobby. Brexit misperceptions. Londres: King's and Ipsos MORI, 2018. Disponível em: https://www. kcl.ac.uk/sspp/policy-institute/publications/Brexit-misperceptions.pdf. Acesso em: 10 dez. 2019.

EU nunca usei vacina contra a gripe e nunca vou usar. [S. I.: s.n], 2019. 1 vídeo (10 min). Publicado pelo canal Dr. Uronal Zancan. Disponível em: https://www.youtube.com/watch?v=hPWO61/1mIE. Acesso em: $10 \mathrm{dez}$. 2019.

FEBRE amarela assista antes de tomar a vacina. [S. I.: s.n], 2018. 1 vídeo. Publicado pelo canal Nova Geração! Compromisso com a Verdade!. Disponível em: https://www.youtube.com/watch?v=WlcQPPn6Rbk. Acesso em: 10 dez. 2019.

GOMES, Wilson da SIlva; DOURADO, Tatiana. Fake news, um fenômeno de comunicação política entre jornalismo, política e democracia. Estudos em Jornalismo e Mídia, Florianópolis, v. 16, n. 2, p. 33-45, jul./ dez. 2019. DOI: https://doi.org/10.5007/1984-6924.2019v16n2p33. Disponível em: https://periodicos.ufsc.br/ index.php/jornalismo/article/view/1984-6924.2019v16n2p33/41754. Acesso em: 10 dez. 2019.

HJARVARD, Stig. Midiatização: conceituando a mudança social e cultural. Matrizes, São Paulo, v. 8, n. 1, p. 21-44, 2014. DOI: https://doi.org/10.11606/issn.1982-8160.v8i1p21-44. Disponível em: https://www.revistas. usp.br/matrizes/article/view/82929. Acesso em: $10 \mathrm{dez} .2019$.

HOCHMAN, Gilberto. Vacinação, varíola e uma cultura da imunização no Brasil. Ciência \& Saúde Coletiva, Rio de Janeiro, v. 16, p. 375-386, fev. 2011. DOI: http://dx.doi.org/10.1590/S1413-81232011000200002. Disponível em: https://www.scielo.br/scielo.php?script=sci arttext\&pid=S1413-81232011000200002\&lng=en\&n rm=iso\&tlng=pt. Acesso em: 10 dez. 2019.

GATES, Bill. Innovating to zero. [S. I.: s.n], 2010. 1 vídeo (27 min). Publicado pelo TED Talk. Disponível em: https://www.ted.com/talks/bill gates innovating to zero/transcript?language=pt-br. Acesso em: 09 jan. 2021. 
JENKINS, Marina Christine; MORENO, Megan A. Vaccination discussion among parents on social media. Journal of Adolescent Health, [s. I.], v. 62, n. 2, p. S86, fev. 2018. DOI: https://doi.org/10.1016/j. jadohealth.2017.11.173. Disponível em: https://www.jahonline.org/article/S1054-139X(17)30702-4/pdf. Acesso em: 10 dez. 2019.

KARLSSON, Michael. The immediacy of online news, the visibility of journalistic processes and a restructuring of journalistic authority. Journalism, [s. I.], v. 12, n. 3, p. 279-295, 2011. DOI: https://doi.org/10.1177\%2F1464884910388223. Disponível em: https://journals.sagepub.com/ doi/10.1177/1464884910388223. Acesso em: 10 dez. 2019

LARSON, Heidi J. et al. Addressing the vaccine confidence gap. The Lancet, Londres, v. 378, n. 9790, p. 526535, jun. 2011. DOI: https://doi.org/10.1016/s0140-6736(11)60678-8. Disponível em: https://pubmed.ncbi.nlm. nih.gov/21664679/. Acesso em: 10 dez. 2019.

LAZER, David M. J. et al. The science of fake news. Science, [s. I.], v. 359, n. 6380, p. 1094-1096, 2018. DOI: www.doi.org/10.1126/science.aao2998. Disponível em: https://science.sciencemag.org/content/359/6380/1094. Acesso em: 10 dez. 2019.

LEMOS, André. Nova esfera conversacional. In: MARQUES, Ângela Cristina Salgueiro et al. Esfera Pública, redes e jornalismo. Rio de Janeiro: E-papers, 2009. p. 9-30.

LEVI, Guido Carlos. Recusa de vacinas: causas e consequências. São Paulo: Segmento Farma, 2013.

LLORENTE, José Antônio. Introdução. Uno, São Paulo, n. 27, 2017. Disponível em: https://www.revista-uno. com.br/numero-27/introducao-6/. Acesso em: 10 dez. 2019.

MELEO-ERWIN, Zoë et al. "To each his own": Discussions of vaccine decision-making in top parenting blogs. Human Vaccines \& Immunotherapeutics, Austin, v. 13, n. 8, p. 1895-1901, 2017. DOI: https://doi.org/10.10 80/21645515.2017.1321182. Disponível em: https://pubmed.ncbi.nlm.nih.gov/28481675/. Acesso em: $10 \mathrm{dez}$. 2019.

NOGUEIRA, Maria Inês; CAMARGO JUNIOR, Kenneth Rochel. A orientalização do Ocidente como superfície de emergência de novos paradigmas em saúde. História, Ciências, Saúde-Manguinhos, Rio de Janeiro, v. 14, n. 3, p. 841-861, jul./set. 2007. DOI: https://doi.org/10.1590/S0104-59702007000300009. Disponível em: https://www.scielo.br/scielo.php?script=sci_arttext\&pid=S0104-59702007000300009. Acesso em: $10 \mathrm{dez}$. 2019.

PÔRTO, Ângela; PONTE, Carlos Fidelis. Vacinas e campanhas: as imagens de uma história a ser contada. Histórias, Ciências, Saúde-Manguinhos, Rio de Janeiro, v. 10, supl. 2, p. 725-42, 2003. DOI: https:// doi.org/10.1590/S0104-59702003000500013. Disponível em: https://www.scielo.br/scielo.php?script=sci arttext\&pid=S0104-59702003000500013\&lng=en\&nrm=iso\&tlng=pt. Acesso em: 10 dez. 2019.

RIEDER, Bernhard. YouTube Data Tools. Versão 1.21. [Amsterdã]: Platform Digitale Infrastructuur Social Science and Humanities, 2015. Disponível em: https://tools.digitalmethods.net/netvizz/youtubel. Acesso em: 10 dez. 2019.

SCHMIDT, Ana Lucía et al. Polarization of the vaccination debate on Facebook. Vaccine, Amsterdã, v. 36, n. 25, p. 3606-3612, 2018. DOI: https://doi.org/10.1016/j.vaccine.2018.05.040. Disponível em: https://pubmed. ncbi.nlm.nih.gov/29773322I. Acesso em: 10 dez. 2019.

SCLIAR, Moacyr. História do conceito de saúde. Physis: Revista de saúde coletiva, Rio de Janeiro, v. 17, n. 1, p. 29-41, jan./abr. 2007. DOI: https://doi.org/10.1590/S0103-73312007000100003. Disponível em: https:// www.scielo.br/scielo.php?script=sci_arttext\&pid=\$0103-73312007000100003\&lng=en\&nrm=iso\&tlng=pt. Acesso em: 10 dez. 2019.

SMITH, Tara C. Vaccine rejection and hesitancy: a review and call to action. Open Forum Infectious Diseases, Nova lorque, v. 4, n. 3, ofx146, 2017. DOI: https://doi.org/10.1093/ofid/ofx146. Disponível em: https://academic.oup.com/ofid/article/4/3/ofx146/3978712. Acesso em: $10 \mathrm{dez} .2019$.

SUCCI, Regina Célia de Menezes. Vaccine refusal-what we need to know. Jornal de Pediatria, Porto Alegre, v. 94, n. 6, p. 574-581, nov./dez. 2018. DOI: https://doi.org/10.1016/j.jped.2018.01.008. Disponível em: https:// www.scielo.br/scielo.php?script=sci_arttext\&pid=S0021-75572018000600574. Acesso em: 10 dez. 2019.

TANGHERLINI, Timothy R. et al. "Mommy Blogs" and the vaccination exemption narrative: results from a machine-learning approach for story aggregation on parenting social media sites. JMIR Public 
Health and Surveillance, Toronto, v. 2, n. 2, e166, 2016. DOI: https://doi.org/10.2196/publichealth.6586. Disponível em: https://pubmed.ncbi.nlm.nih.gov/27876690/. Acesso em: 10 dez. 2019.

URGENTE! Médico faz grave alerta vacina h1n1 destroí a imunidade e da câncer-será possivel???. [S. I.: s.n], 2019. 1 vídeo. Publicado pelo canal Pátria Evangélica de Deus. Disponível em: https://www.youtube. com/watch?v=BdNM4f3s8tQ. Acesso em: 10 dez. 2019.

WARDLE, Claire; DERAKHSHAN, Hossein. Information disorder: toward an interdisciplinary framework for research and policymaking. Strasbourg Cedex: Council of Europe, 2017. E-book. Disponível em: https://rm.coe.int/information-disorder-toward-an-interdisciplinary-framework-for-researc/168076277c. Acesso em: 10 dez. 2019.

WASZAK, Przemyslaw M.; KASPRZYCKA-WASZAK, Wioleta; KUBANEK, Alicja. The spread of medical fake news in social media-the pilot quantitative study. Health Policy and Technology, [s. I.], v. 7, n. 2, p. 115-118, jun. 2018. DOI: https://doi.org/10.1016/j.hlpt.2018.03.002. Disponível em: https://www.sciencedirect.com/science/article/abs/pii/S2211883718300881. Acesso em: 10 dez. 2019.

VEJA a verdade por detrás da vacina da febre amarela: Hangout Dr Lair Ribeiro. [S. I.: s.n], 2018. 1 vídeo (92 min). Publicado pelo canal U MIÓ QUE TÁ TENO. Disponível em: https://www.youtube.com/ watch?v=KdCCbazbKAl. Acesso em: $10 \mathrm{dez} .2019$.

YIANNAKOULIAS, Nikolaus; SLAVIK, Catherine E.; CHASE, Monika. Expressions of pro and antivaccine sentiment on YouTube. Vaccine, [s. I.], v. 37, n. 15, p. 2057-2064, abr. 2019. DOI: https://doi. org/10.1016/j.vaccine.2019.03.001. Disponível em: https://www.sciencedirect.com/science/article/pii/ S0264410X19302920?via\%3Dihub. Acesso em: 10 dez. 2019.

YOUTUBE. Youtube em número: mais de dois bilhões de usuários. [São Paulo]: Youtube, c2021. Disponível em: https://www.youtube.com/int/pt-BR/about/press/. Acesso em: 10 dez. 2019. 